\title{
Revistas andaluzas contemporáneas (1974-1993): pequeñas historias de un gran fracaso
}

\author{
Dr. Ramón Reig \\ Profesor Titular de Estructura de la Información Periodística \\ Facultad de Ciencias de la Información \\ Universidad de Sevilla
}

En el periodo 1974-1993 aparecieron en Andalucía una serie de revistas ninguna de las cuales logró consolidarse como publicación periódica de carácter regional. Las causas de este hecho pueden concretarse en dos puntos: 1. El tejido empresarial andaluz ha sido tradicionalmente débil y esta debilidad se observa mucho más acusada en el campo de las industrias culturales, en este caso en el de la prensa (revistas y diarios con proyección regional); 2. La conciencia regionalista-nacionalista del receptor ha sido y es muy débil y a ello se une el bajo índice de lectura de los andaluces (una media del 75 por 1.000 en cuanto a prensa). De todas formas, las publicaciones que se estudian a continuación tuvieron el mérito de ser las primeras, después de la época franquista, en abordar temas tan ignorados entre la población como el origen y desarrollo del andalucismo histórico y otras teóricas señas de identidad de la comunidad autónoma andaluza.

\section{Introducción}

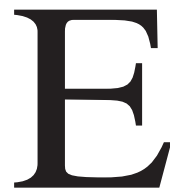

1 período 1974-1993 se ha caracterizado en Andalucía por el sistemático fracaso de todo intento que, partiendo de la iniciativa privada, pretendía consolidar una revista de alcance regional y que, además, se extendiera a los núcleos emigratorios de Madrid, Barcelona y País Vasco. La filosofía que animaba a dicha iniciativa bien podría ser la que constata en 1978 el director del semanario Algarabía, Francisco Lancha: "Resulta que un grupo de hombres de esta tierra, vinculados a ella por los más diversos y heterogéneos motivos, nos hemos propuesto la obligación de sacar adelante un medio de comunicación que refleje las necesidades e intereses andaluces abarcando el espectro político-social y político-económico de este amplio y diverso trozo del solar español, llamado Andalucía"'.

\footnotetext{
1 LANCHA, Francisco: "Carta del director”, Algarabía, noviembre de 1978.
} 
Nos proponemos a continuación llevar a cabo un repaso global acerca de las características de las principales revistas andaluzas, esto es, publicadas con capital andaluz, que aparecieron en el mercado durante el período cronológico indicado más arriba.

\section{La ilustración regional}

Cronológicamente, la primera de ellas es La Ilustración Regional. La autodenominada Gran Enciclopedia de Andalucía, dice de esta publicación:

"Revista andaluza que comenzó a publicarse en septiembre de 1974 y cesó en enero de 1976. Aunque sólo publicó 16 números "La Ilustración Regional" tiene un lugar en la historia reciente del periodismo andaluz, ya que fue la primera publicación que en los años setenta se planteó una información sobre Andalucía en su totalidad, alejada además de los tópicos usuales entonces en la mayoría de los medios informativos de la región. Aunque sus planteamientos empresariales rozaron en algún aspecto el elitismo, (era revista mensual, considerablemente más cara que la mayoría de las publicaciones del momento), "La Ilustración Regional" ofreció en su corta historia -que incluye un número secuestrado, algunas páginas cortadas cuando ya estaba impresa la publicación y muchas presiones- una visión nueva de Andalucía; gracias a esta publicación comenzaron a conocer muchos andaluces de las jóvenes generaciones la existencia del andalucismo histórico. Pese a que lanzó pocos números, en sus páginas quedó la colaboración de un amplio grupo de andaluces que pronto iban a tomar muy diferentes rumbos ideológicos. Su colección resulta hoy muy valiosa como testimonio del pensamiento de los andaluces sobre Andalucía en aquella coyuntura histórica que fue el último año del franquismo y las primeras semanas de transición hacia la democracia"2.

Sobre La Ilustración Regional ha escrito el periodista y profesor Antonio Checa Godoy: "La etapa de transición que abre el paso de Pío Cabanillas por el Ministerio de Información y Turismo -el "aperturismo"- tiene una importante huella en Andalucía: la aparición en el otoño de 1974 de La Ilustración

\footnotetext{
Ilustración Regional, La: Gran Enciclopedia de Andalucía, tomo V, pág. 2.014. Promociones Culturales Andaluzas. Dep. Legal Granada, 1979. Realización en Sevilla.
} 
Regional, un mensual de notable presentación y primera publicación que se interroga sobre la Andalucía de nuestros días y se plantea con rigor crítico sus problemas reales. En sus dieciséis números (muere en enero de 1976) conoce secuestros y sanciones diversas. Es todo un hito en el periodismo actual del sur, pues consigue integrar a la izquierda y a la derecha democrática, pero se trata de una revista muy deficitaria"3.

Ciertamente, el nombre de la revista hace honor a sus impulsores. Tal vez siguiendo con esa especie de "tradición lamentable" que consiste en que el tratamiento y profundización del andalucismo o nacionalismo andaluz, como desee denominarse a la toma de conciencia previo conocimiento de la Historia de Andalucía, siempre se ha ceñido a una minoría más o menos ilustrada, la revista de la que tratamos contó al frente con nombres tales como Jaime García Añoveros, Soledad Becerril o Rafael Atienza. Todos ellos pertenecían y pertenecen a una clase social andaluza acomodada que, con la llegada del sistema postfranquista, iban a alinearse con las posiciones políticas llamadas "de centro". Tanto Soledad Becerril como García Añoveros llegaron a ser ministros con la Unión de Centro Democrático (UCD), formación multi-ideológica que, encabezada por Adolfo Suárez, sirvió al sistema para seguir ostentando el poder, arrinconando a los elementos humanos que habían tenido relación directa con el franquismo en otras formaciones como Alianza Popular o Fuerza Nueva, y dejando así el paso libre a una amalgama de liberales, democristianos y franquistas más o menos "vírgenes" que se mantuvieron en el poder desde 1977 hasta 1982, año en que irrumpió abrumadoramente el PSOE. La UCD acabó desintegrándose ${ }^{4}$.

No obstante, las firmas que aparecieron en la revista nos demuestran un pluralismo real de ideas. Bajo la dirección, primero, de Javier Smith Carretero, y, después, de M.A. Agea Amador, el lector pudo acceder a textos de: Soledad Becerril, Antonio Burgos, José Aguilar Villagrán, C. Castilla del Pino, M. Ramón Alarcón, Isidoro Romero, Amparo Rubiales, Nicolás Salas, J.M. González Ruiz, Ignacio Romero de Solís, Eduardo Chinarro, Roberto Mesa, Alfonso Lazo, Emilio Pérez Ruiz, Antonio Ramos Espejo, Antonio Checa y Francisco Acosta, entre otros.

3 CHECA GODOY, Antonio: “La prensa en Andalucía: Crónica de una decadencia”, en VV.AA: Los andaluces. Ed. Itsmo, Madrid, 1980, pág. 541.

4 En la actualidad, Soledad Becerril milita en las filas del PP y es alcaldesa de Sevilla, mientras que Jaime García Añoveros, catedrático de Derecho en la Universidad de Sevilla, está vinculado al grupo PRISA. 


\section{Pregional}

No1· SEPTIEMBRE, 1974 - 5DPTAS
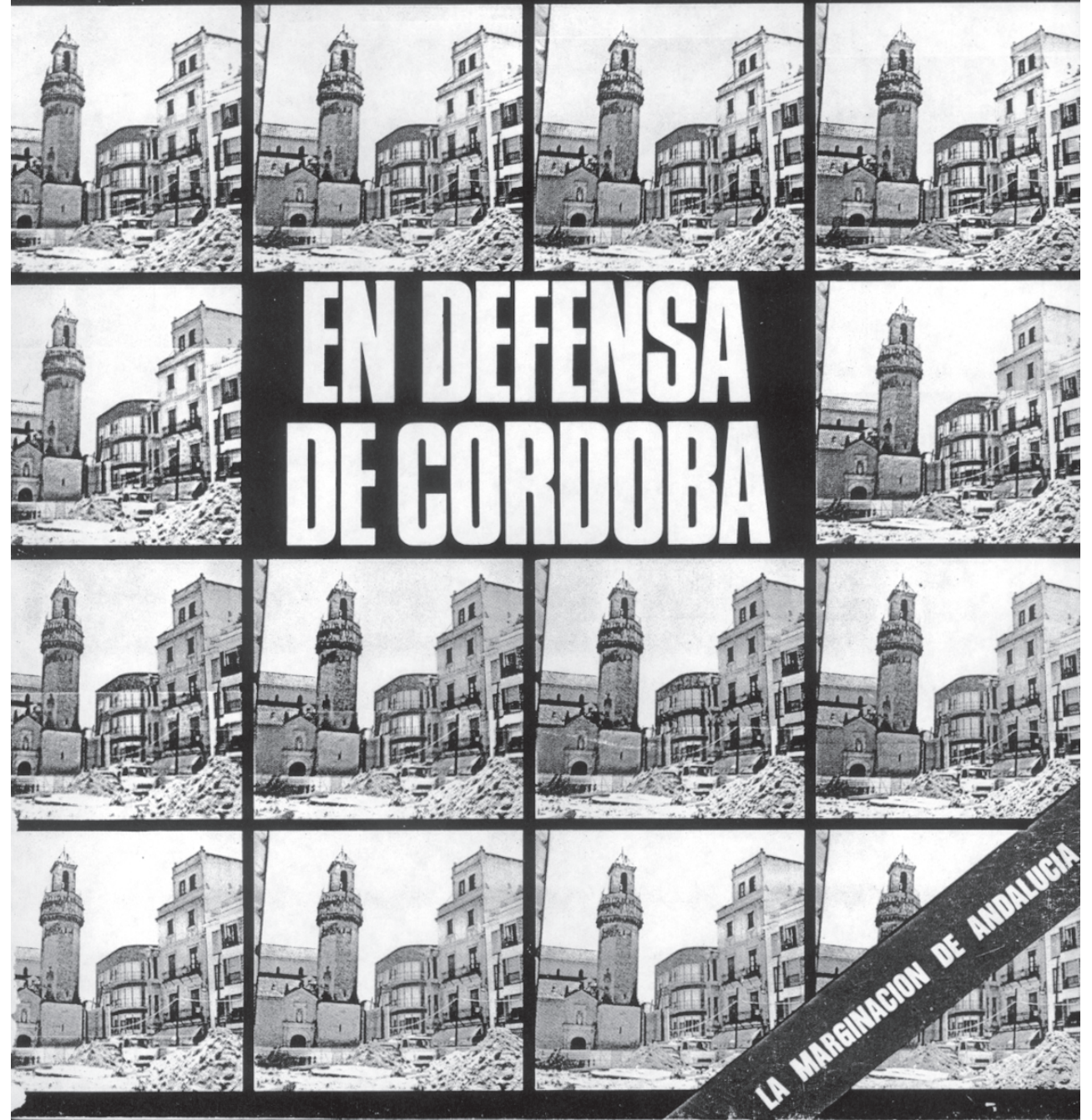
Algunos impulsores de La Ilustración Regional pertenecían pues a miembros ilustrados de la clase acomodada andaluza que, por otra parte, y paradójicamente en relación con esa defensa que se hacía de Andalucía a través de la revista, nunca hasta el momento ha conseguido alinearse en torno a un partido andaluz. De hecho, a finales de los setenta, el también ex ministro de la UCD Manuel Clavero Arévalo fundó un partido, Unidad Andaluza (UA), que hubo de disolver por la falta de apoyo de los llamados poderes fácticos andaluces. Ya a mediados de los setenta, el mismo Clavero Arévalo había impulsado el Partido Social Liberal Andaluz (PSLA), que acabó siendo absorbido por la UCD.

El hoy llamado Partido Andalucista (PA) nunca gozó de la confianza del poder real andaluz. No en vano ha experimentado numerosos vaivenes en su historia: de llamarse en la semiclandestinidad Alianza Socialista de Andalucía (ASA), con algunas conexiones con el PCE, pasó a llamarse Partido Socialista de Andalucía (PSA); más tarde a esta denominación le añadió el matiz Partido Andaluz (PSA-Partido Andaluz); finalmente, llegamos al PA de hoy, en un intento de captar las voluntades electorales del sector más amplio posible de la población andaluza.

\section{Tierras del Sur}

Estamos ante un caso de revista ideológicamente similar al anterior pero con unas miras empresariales más amplias. La empresa editora de la revista es Rocafer del Sur, S.A., cuyo nombre, Rocafer, es una especie de acróstico de los apellidos Rodríguez, Carmona, Fernández. En resumidas palabras, es una familia acomodada sevillana, los Fernández-Palacios, la que iba a impulsar esta publicación con la inestimable aportación periodística del sacerdote José María Javierre, hombre que, a pesar de haber nacido en Aragón, está ya profundamente enraizado en Andalucía y lo está como puede suponerse desde hace no pocos años (ha sido incluso pregonero de la Semana Santa de Sevilla, al margen de que en el tardofranquismo dirigió El Correo de Andalucía, de Sevilla, imprimiéndole una línea liberal que ha pasado a la historia de la prensa andaluza).

Tierras del Sur, cuya existencia comprende el período 1976-1979, comenzó editándose con tamaño tabloide y un precio asequible. Su tirada se hacía a tres colores: negro, verde y rojo. En su última etapa pasó a publicarse con formato revista. En favor de Tierras del Sur está haber sido la publicación andaluza que, junto al diario El Correo de Andalucía, dio a conocer al gran público en 1977-78, en eso que en argot periodístico se denomina 


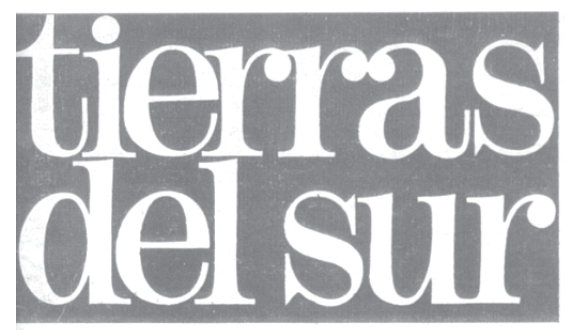

\section{DESARROLLO = PAZ}

\section{CORDOBA FRIO POLITICO}

NUM. 93 / 29 - MARZO / $1978 \bigcirc 50$ PESETAS

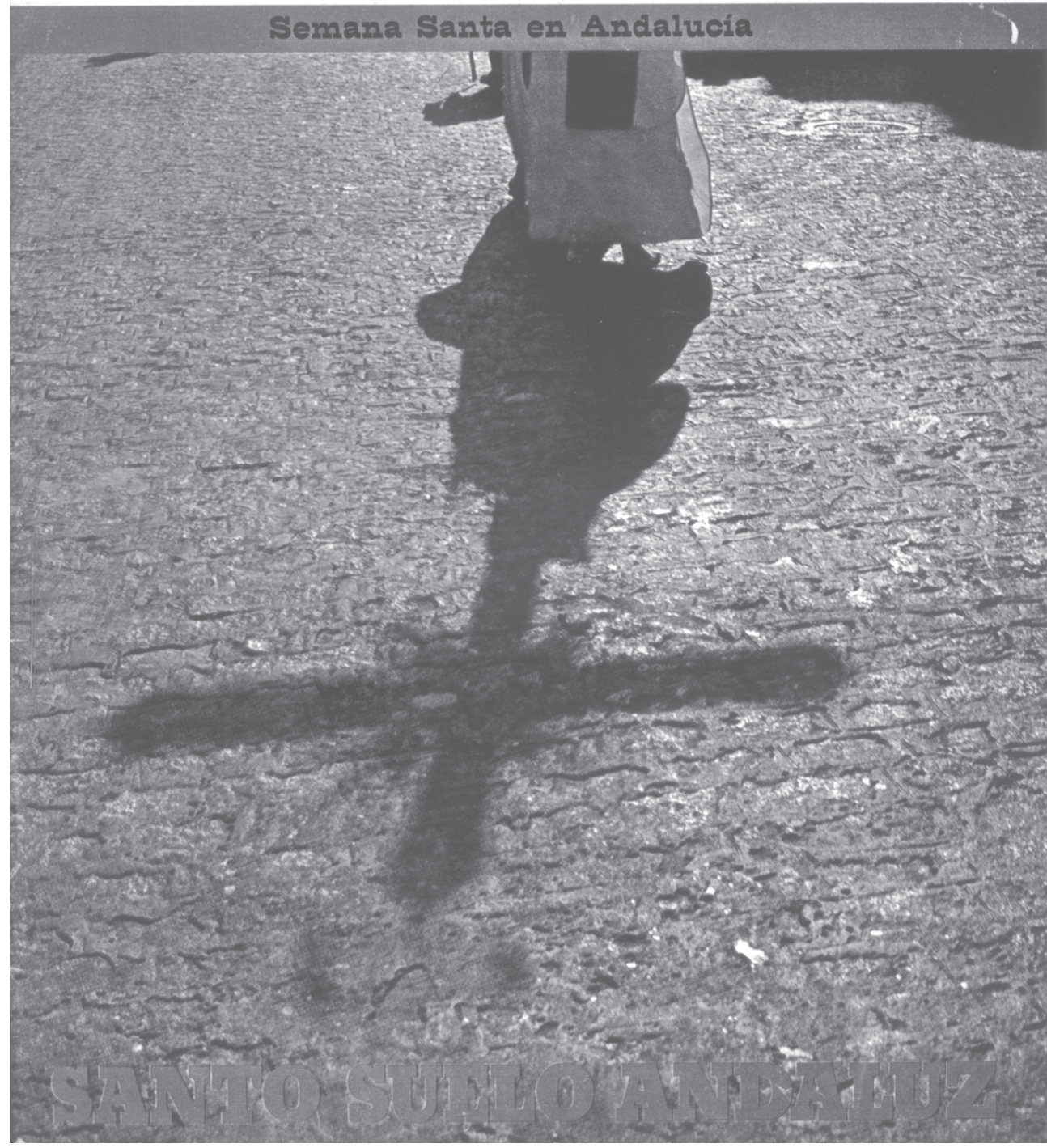


"primicia nacional e internacional", la existencia en la sierra cordobesa del Cementerio Nuclear de Hornachuelos o del Cabril. Fue un descubrimiento del corresponsal de la revista en Córdoba, el poeta y periodista, Sebastián Cuevas, ya fallecido, quien recorrió un amplio trecho de la sierra, de acuerdo con las informaciones de sus fuentes, hasta encontrar lo que buscaba.

La antes citada Gran Enciclopedia de Andalucía, obra que se elaboró tras la desaparición de la revista impulsada prácticamente por las mismas personas, dice de Tierras del Sur:

"Semanario andaluz. Nació en mayo de 1976. Durante tres años fue "la voz de Andalucía", como rezaba el subtítulo: cauce donde se exponían y denunciaban los problemas, inquietudes, aspiraciones e injusticias de nuestras tierras del sur. La revista mereció ser nominada en 1976 "Sevillano del año". Publicación de talante liberal, todas las opiniones y tendencias tenían cabida en la época de transición hacia las libertades democráticas. "Tierras del Sur" sirvió de plataforma para el diálogo entre las corrientes políticas y sociales de Andalucía, con la única condición del respeto mutuo y un servicio leal a los intereses de nuestro pueblo. El semanario logró la difusión regional, cubriendo no sólo las ocho provincias de Andalucía, sino también amplios sectores de nuestra emigración. Entre los servicios prestados por "Tierras del Sur" destaca haber publicado una serie de cinco reportajes sobre una figura prácticamente olvidada desde la guerra civil: Blas Infante. Estos reportajes, debidos a José Luis Ortiz de Lanzagorta, sirvieron de fermento para la espiral de noticias y comentarios aparecidos luego en torno al padre de la patria andaluza"s.

\section{Torneo}

A pesar de que la existencia de las revistas andaluzas de la transición fue efímera, durante un tiempo determinado llegan a subsistir tres semanarios: Tierras del Sur, Algarabía y Torneo. Esta última, con altos y bajos en cuanto a su presencia en la calle, como les sucedió a todas, salió a la venta durante un año aproximadamente (1976-77), dirigida por Federico Villagrán, que era además accionista y editor de la misma.

Villagrán había sido anteriormente director del diario sevillano El Correo de Andalucía. Puede decirse con poco temor a equivocarse que fue

\footnotetext{
Tierras del Sur: Gran Enciclopedia de Andalucía, tomo VII, pág. 3.108. Promociones Culturales Andaluzas, Dep. Legal Granada, 1979. Realización en redacción de Sevilla.
} 

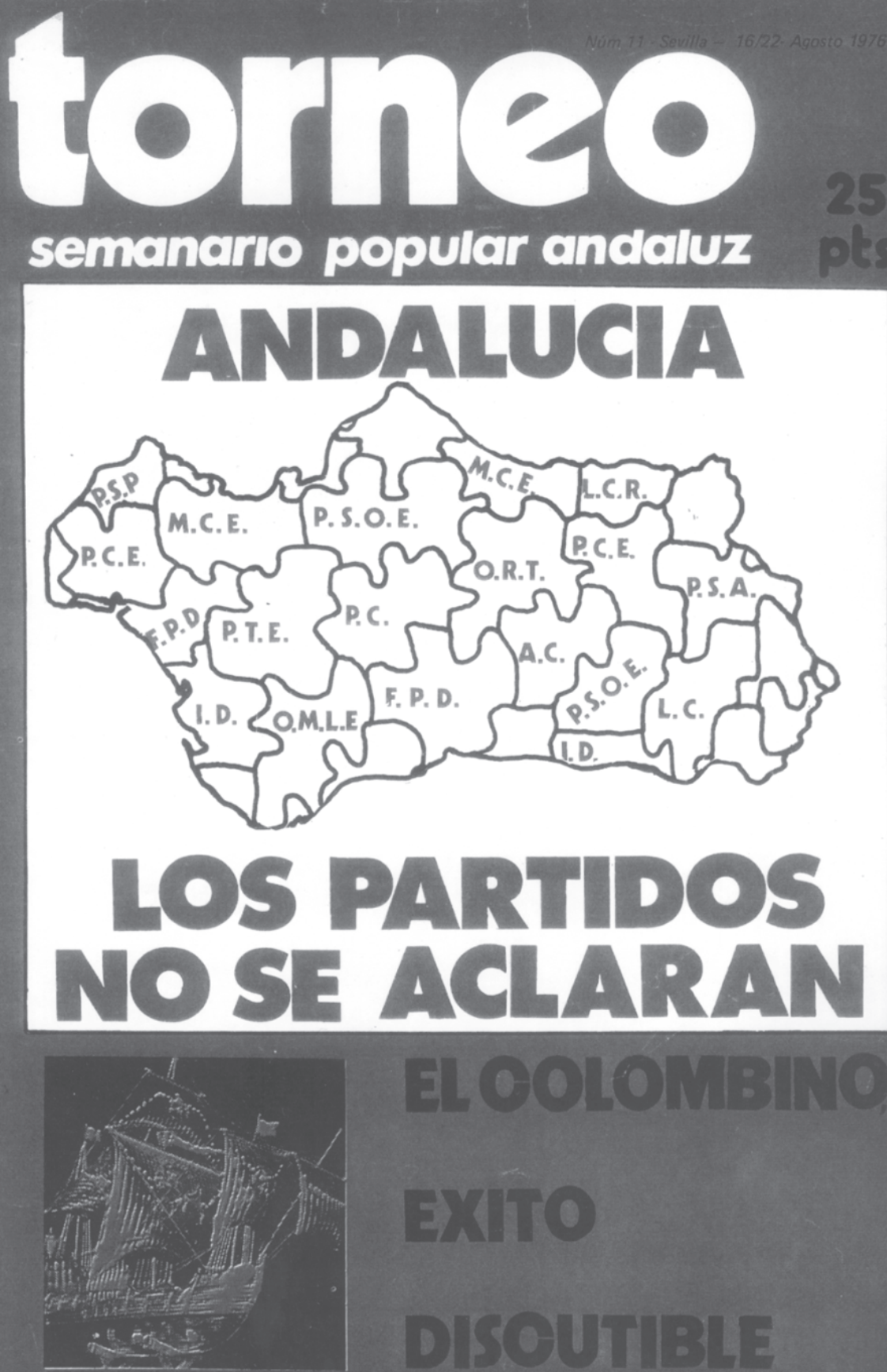
entonces (1974-75) la época de mayor esplendor de este diario en los últimos veinte o veinticinco años en cuanto a tirada e influencia. Villagrán configuró una tercera página de opinión en la que podían leerse firmas tales como las de Isidoro Moreno Navarro, hoy catedrático de Antropología de la Universidad de Sevilla y entonces militante destacado del que se denominó Partido del Trabajo de España (PTE), organización muy activa en la clandestinidad franquista junto a su rama juvenil, la Joven Guardia Roja, ambas de orientación maoísta; otras firmas fueron las de Tomás Iglesias, abogado, ya fallecido, pero entonces militante asimismo del PTE; Manuel Ramón Alarcón, catedrático hoy de Derecho y entonces militante del selecto y minoritario partido que se denominó Acción Comunista (AC) ${ }^{6}$. Otros nombres vinculados esta vez al PSOE aparecieron en aquella "tercera" de $E l$ Correo de Andalucía: destaquemos a José Rodríguez de la Borbolla y a José Luis López López, éste último catedrático de Filosofía en la Universidad de Sevilla. Borbolla, ex presidente de la Junta de Andalucía, es hoy profesor titular en la Facultad de Derecho de Sevilla y concejal del PSOE en el Ayuntamiento hispalense.

Lo más sorprendente (sorprendente ahora en cierta medida y menos sorprendente entonces), sucedió cuando en 1974, con motivo del triunfo en Portugal de la llamada "Revolución de los claveles", Federico Villagrán publicó en primera página de $\mathrm{El}$ Correo y con gran alarde tipográfico que aproximadamente una docena de miles de marines norteamericanos se encontraban frente a las costas portuguesas dispuestos a invadir el país y terminar así con el dominio momentáneo que las corrientes comunistas ejercían sobre aquella revolución que dio al traste con la dictadura salazaristacaetanista, dominio que, como es sabido, terminó siendo arrinconado. El caso es que la noticia de marras, considerada como cierta aún hoy por el propio Villagrán $^{7}$, si bien su certeza no debe sorprendernos a raíz de la experiencia histórica, dio con el director del diario sevillano en la cárcel situada por cierto prácticamente frente al edificio del periódico.

Ya en 1977 le vemos al frente de Torneo. Detrás de Torneo aparece la sociedad Prensa y Copistería, S.A. que, además de la revista de Villagrán, tenía la misión de editar entonces El Socialista. Torneo es pues una revista

\footnotetext{
Aclaremos que lo de "selecto" está dicho por las directrices leninistas que seguía esta formación en el sentido de dar cobijo en su interior a pocos militantes pero con una formación cultural más o menos amplia en el plano político teórico.

7 En declaraciones a quien suscribe.
} 


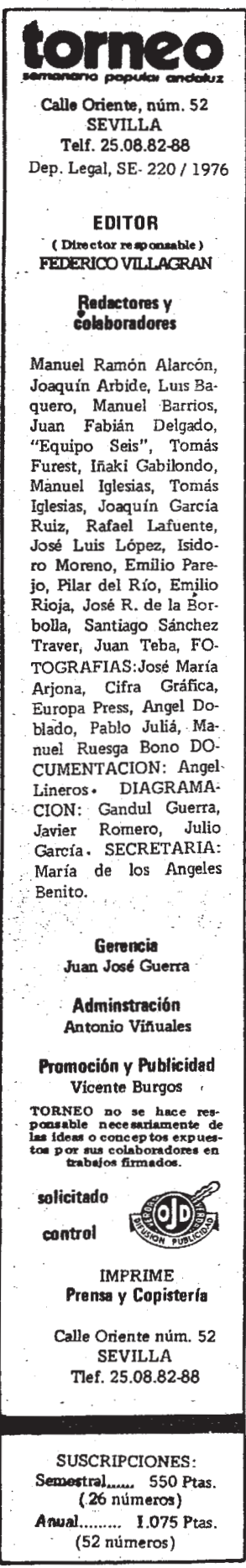

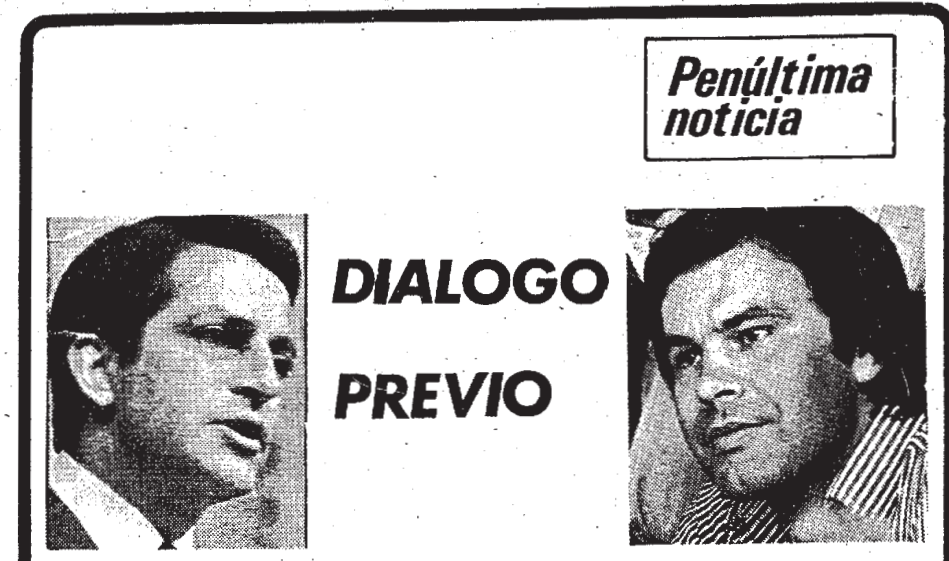

- A semana última registra un acontecimiento, en la vida política nacional, que el decurso de $\angle$ los hechos venía haciendo poco menos que insoslayable: el encuentro del Presidente del Gobierno con el lider del Partido Socialista Obrero Español. Trás la entrevista de Adolfo Suárez con el ex-ministro Ruiz Jiménez (hoy protagonista de Izquierda Democrática), y las anteriores del 'Rey con Gil Robles', como asimismo del entonces ministro de Gohernación, Fraga, con el profesor Tierno, estaba por ver hasta donde el postfranquismo era capaz de llegar en sus intentos de diálogo con la Oposición.

4. L fin, el Gobierno ha contactado con la Izquierda auténtica, con todo el aval de la Europa 4 socialista detrás, el respaldo del mundo democrático y el respeto de las llamadas democracias populares; la izquierda que enarbola el puño cerrado, que entona "La Internacional" y que en ni un sólo punto programático renuncia a la lucha de clases, a la implantación universal del Socialismo tal como fue concebido por Marx y adecuado a las realidades espeñolas por figuras tan colosales como Pablo Iglesias, Indalecio Prieto, Largo Caballero, Julian Besteiro... 0 se.puede negar realismo al presidente Suárez. Tampoco, al menos por el gesto, propusitos
de encontrar fórmulas de convivencia entre los españoles. Más nadie se haga ilusiones precoces. El comunicado del P.S.O.E. ha sido bien contundente. La entrevista " se enmarca dentro de las relaciones del Gobierno con la Opısición, como dialógo previo a un posible proceso de negociación que conduzca a una democraciu plena en nuestro pais". Y esa democracia plena -bien lo conoce el Gobierno y los españoles todos- pasa por un organișmo oficioso que se autodenomina Coordinacion Democrática.

Y si bien, como apuntaban hace poco los comentaristas políticos, en el último comunicado de Coordinación se descubría un tono en ciesta manera menos contundente que en otros anteriores, de ahí a la posibilidad de una mutación en sus planteamientos media sencillamente la razón de ser o no ser el propio organismo.

A posible moderación en aspectos formales, hoy por hoy, sólo puede ser entendida como respuesta a una actitud similar en la otra parte antagonista. Nada más.

- L Gobierno anterior pretendió sembrar inquietudes al discriminar en su política de detenE ciones, llegando incluso a desenterrar viejas y olvidadas divisiones en el seno de algunus partidos de Coordinación. La anécdota pasará a la historia de los mil ardides del Sistema ell su intento de perpetuarse. Todo fracasó.

DOLFO Suárez parece prefiere el siempre claro sendero del entendimiento directo. Cabría pensar se trata de una nueva táctica -hastante más elegante, eso si- con los mismos objetivos. Con esperanza, queremos creer que no es asi, y que el actual Gabinete no pasaráa a la historia por haber ensayado otro tipo de enredos. El país necesita cualquier cosa menos trampas. 
andaluza de la transición pero, a diferencia de La Ilustración Regional, Tierras del Sur e incluso Algarabía, se trataba de una revista de orientación claramente de izquierdas aunque relativamente independiente en cuanto a que no estaba adscrita a ningún partido como era el caso del mensual Andalucía Libre, órgano oficial del Partido Socialista de Andalucía, dirigido en una época -su mejor época por cierto- por un brillante periodista: Manuel Prados ${ }^{8}$.

Socios de Prensa y Copistería eran Federico Villagrán y Francisco Palomino, éste último militante del PSOE y cuñado de Felipe González. Como gerente aparecía Juan Guerra González, militante del PSOE y hermano del dirigente Alfonso Guerra. Desavenencias, falta de experiencia profesional tal vez como consecuencia de las condiciones históricas de semi-clandestinidad, fallos técnicos, etc., dieron al traste con la revista. En su cierre influyó además el miedo a anunciarse en ella (el único empresario destacado de Sevilla que lo hizo fue Gabriel Rojas, mientras que los demás no lo hacían por rechazo o por temor). La revista es cierto que fue objeto de especial seguimiento por los segmentos sociales dominantes. Su sede fue asaltada y destruida en gran parte dentro de una operación oscura aún no clarificada. Recordamos que se habló desde una obra de los ultraderechistas hasta de una especie de fruto de una guerra interna entre los sectores que sostenían la publicación ${ }^{9}$.

Sea como fuere, lo cierto es que la revista acabó desapareciendo. Antes, Federico Villagrán llegó a entablar conversaciones con Tierras del Sur, con el PSOE e incluso con el PCE. Ninguna de estas conversaciones fructificó. A Torneo se la consideraba vinculada al PTE. Villagrán solicitó en efecto ayuda a este partido (ayuda financiera se entiende). El PTE respondió a esta demanda con 300.000 pesetas, cantidad que, como puede suponerse, incluso en aquellos años tan sólo sirvió para imprimir un número. Al final, los hechos indican que Torneo acaba por desaparecer mientras que El Socialista permanecía, evidentemente por contar con un respaldo mucho mayor.

A pesar de todo lo dicho, lo que nos ha llamado más la atención de todo este esbozo de historia es la idea o punto de partida con que nace la revista. En efecto, Federico Villagrán pretendía lo que, más tarde, iban a lograr todos los diarios: romper el monopolio informativo de las "Hojas del Lunes", semanarios por lo general de tamaño tabloide y papel periódico editados por

\footnotetext{
8 Andalucía Libre ha reaparecido en 1993 con continente y contenido ampliamente deficientes y no comparables a los de los años últimos de la década de los 70 .

9 Hemos de recurrir a vivencias propias porque no existen datos fidedignos sobre el tema.
} 
las asociaciones de la prensa en todas y cada una de las provincias españolas con información fundamentalmente deportiva y taurina.

Las asociaciones de la prensa eran aún cobijo de muchos profesionales de la información especialmente mimados por el régimen franquista o simplemente de ciertos personajes que habían accedido al carnet profesional, que era a la vez un elemento de control político, por simple fidelidad a los "principios fundamentales del movimiento" insurreccional del 18 de julio de 1936.

Con este panorama, Villagrán consideró que Torneo podía aparecer los lunes con información deportiva y taurina que sirviera de "gancho" y/o reclamo. Ahora bien, esta información sería completada en principio, apareciendo temas como el conflicto y la situación del campo andaluz, los asuntos políticos andaluces más espinosos, reportajes sobre cuestiones como la de los sacerdotes que habían contraído matrimonio, las actuaciones contundentes de la Guardia Civil en algunas acciones jornaleras, etc. Era por tanto una línea "rupturista" que terminó en un año como mucho.

De Tierras del Sur y de Torneo ha escrito Antonio Checa Godoy: Tierras del Sur es "el primer semanario de ámbito regional con ideología de centro izquierda (...). Torneo, también semanario, con difusión centrada en Andalucía occidental, está ideológicamente más a la izquierda que aquél, pero menos regionalista. Torneo, que en su corta trayectoria conoce diversas peripecias, incluida la destrucción de sus talleres, que obliga a una suspensión temporal de la publicación, cesa a principios de 1977, en tanto Tierras del Sur que, como ocurriera con La Ilustración Regional, se imprime fuera de Andalucía por falta de instalaciones adecuadas y de precios competitivos en la región, se mantiene y lanza en torno a los 12.000 ejemplares" 10 .

\section{Algarabía: una fugaz «aventura»}

En este contexto de la Historia de Andalucía y del periodismo andaluz nace Algarabía. Su número 0 tiene fecha de noviembre de 1978. Si Torneo y por supuesto La Ilustración Regional ya habían cesado en su publicación aún se mantenía Tierras del Sur que iba a sobrevivir incluso a la propia Algarabía. Entre otros puntos de Andalucía, la revista se presentó en el Hotel Inglaterra de Sevilla. En una foto publicada en el número 2 de la publicación

\footnotetext{
${ }^{10}$ Checa Godoy, op. cit., pág. 542.
} 


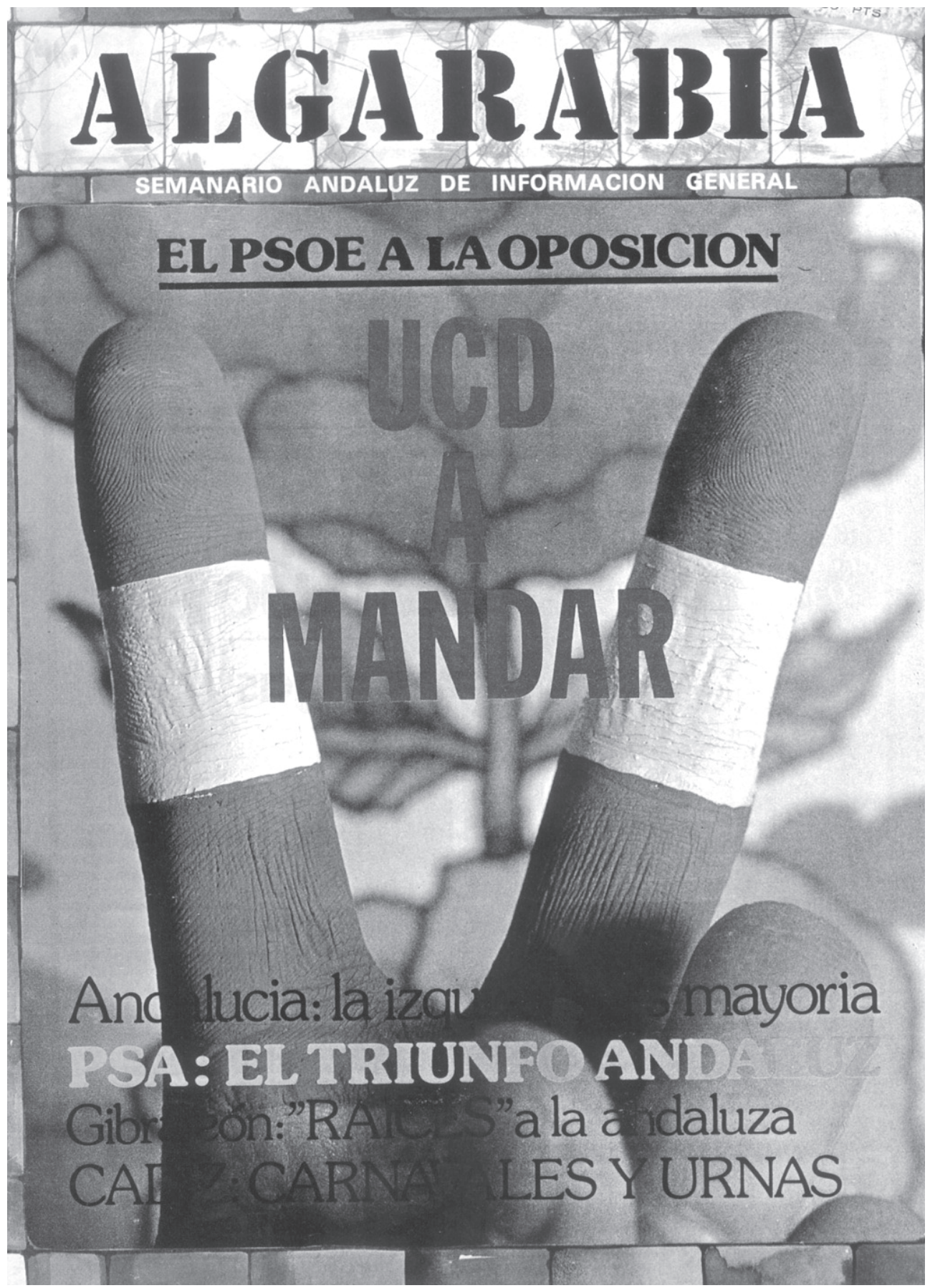


(pág. 4) los directores de ambas revistas, José María Javierre y Francisco Lancha, se saludan en el citado acto de presentación deseándose una suerte que no acompañará, en el seno de una tónica general que aún prosigue como lo demuestra el hecho de que no exista una revista de información general auténticamente andaluza y que proyectos como el de Diario 16 edición de Andalucía aún no se hayan implantado del todo. Como mucho, existen delegaciones en Andalucía de grandes grupos de Comunicación estatales procedentes casi en exclusiva de Madrid $^{11}$.

Algarabía fue la revista andaluza de la transición de vida más corta: sólo llegó a editar cinco números incluyendo el número 0 , que aparece sobre todo como promocional y/o experimental. En pocos estudios sobre la prensa reciente andaluza encontrará el público noticias de Algarabía. Y es que, al margen de su leve vida, la revista poseía una característica esencial: su redacción central no estaba en Sevilla como las que hemos citado aquí, sino que se encontraba en la otra gran ciudad del Sur de España: Málaga. Se imprimía incluso en Málaga y desde allí se distribuía.

Algarabía va a ser pionera por tanto en romper eso que en la actualidad se conoce despectivamente como "centralismo sevillano". Su finalidad periodística va a consistir en aglutinar, informativamente hablando, a Andalucía, en aprovechar periodística y empresarialmente un incipiente y débil sentimiento andaluz. Esta debilidad va a desanimar a sus impulsores muy pronto, tal vez porque el ánimo de todos ellos no va a ser el mismo.

La editora de Algarabía es la Sociedad Andaluza de Ediciones, S.A. Sus accionistas se encarnan en las personas de su director, el periodista Francisco Lancha; en otra periodista malagueña, Carmen Villodres; en Antonio Mata, abogado y empresario de Jaén; y en Vicente Rodríguez Aulet, empresario también, promotor turístico en Málaga. El fundador es el propio Lancha que, aunque nacido en Marruecos, está fuertemente vinculado a Málaga.

\footnotetext{
${ }^{11}$ Cuando a mediados de 1998 revisamos este texto, observamos que Diario 16 Andalucía intentó "independizarse" de Madrid; sus ventas se centraban sobre todo en Sevilla, unas ventas e influencia que, a pesar de la ilusión que la entrada de capital andaluz, en forma de aval, despertó en su día (1997), no lo han librado del "desastre" global del Grupo 16. En 1997, el director y subdirector de la "etapa andaluza” del diario, José Aguilar y Rafael Rodríguez, abandonaron el periódico, cuya cabecera no entró en la venta de la que fue objeto en enero de 1998 Diario 16, precisamente porque los accionariados de Madrid y Sevilla no coincidían. La aportación andaluza de capital (procedente del empresario onubense Fernández Vizcaya) tampoco dio sus frutos. El periódico desapareció a finales de 1997 y en abril de 1998 salió a la calle Diario de Andalucía, de capital mayoritariamente andaluz, vinculado al empresario Manuel Domínguez, de proyección regional y con la pretensión de suceder a Diario 16 Andalucía (su redacción procedía de esta cabecera). Por otra parte, aún es pronto para hacer balance con la debida perspectiva de las ediciones andaluzas de El País y El Mundo, aparecidas en 1995 y 1996, respectivamente. Tampoco el tema es materia de este trabajo.
} 


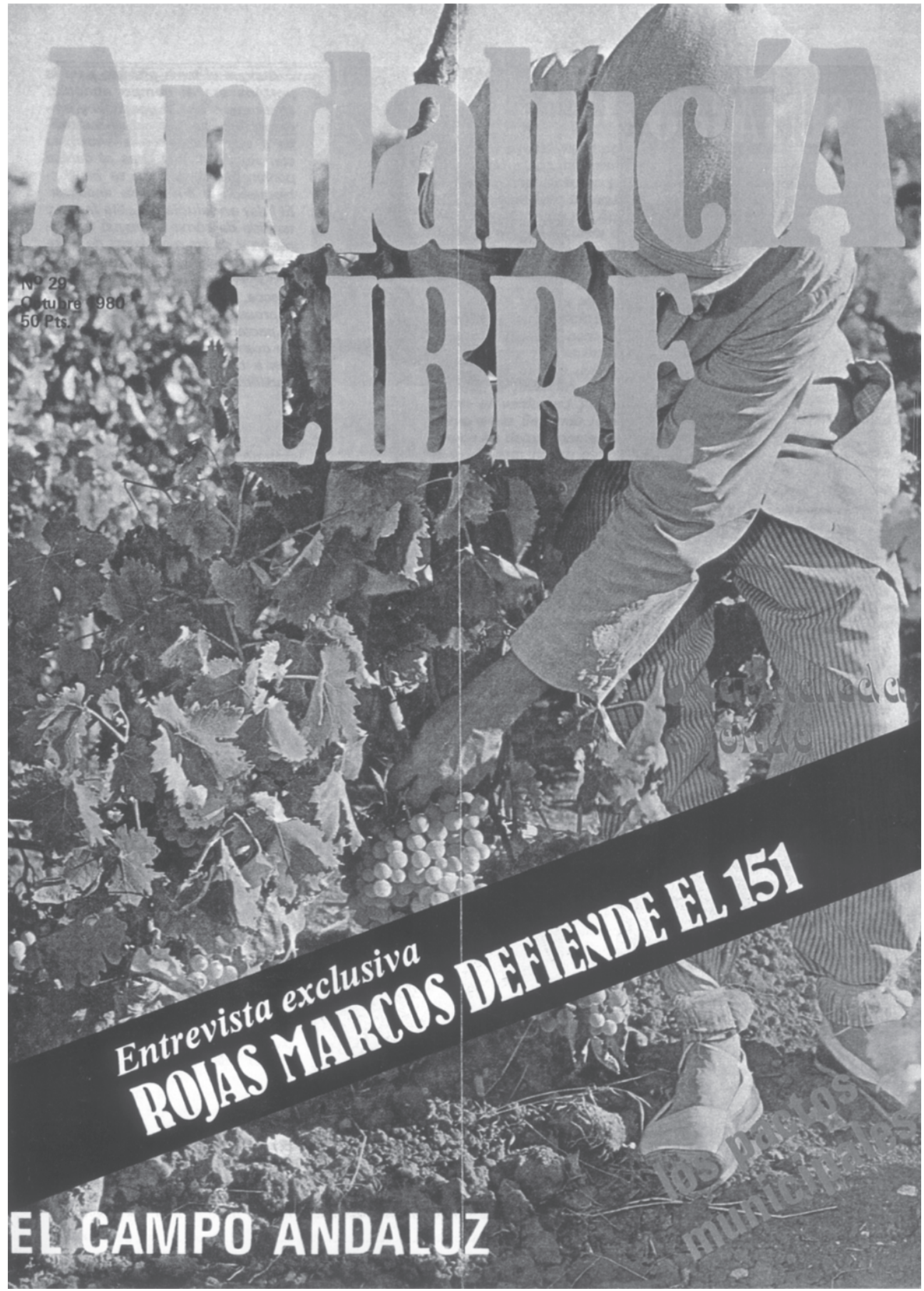


La tirada de Algarabía se situó alrededor de los 7.000 ejemplares. Las ventas aproximadas fueron de entre 1.600 y 1.800 ejemplares en Sevilla (en determinadas ocasiones), mientras que en Córdoba, Cádiz y Granada las ventas se situaban sobre los 300 ejemplares. La aceptación mayor estaba en la propia Málaga: unos 2.000 ejemplares ${ }^{12}$. De cualquier forma, aunque definido como semanario, Algarabía iba a tener una notable acronicidad en sus salidas al público con evidentes defectos de maquetación y de contenido, como, por ejemplo, no especificar, salvo en el número 0 , ni el número de orden de publicación ni el año, tan sólo unas semanas que además no eran correlativas. Incluso los sumarios de la revista, al margen de su deficiente composición y maquetación, no contienen temas de interés que estaban en el mismo número que anuncian.

La revista poseía, además de la redacción central en Málaga, corresponsales en todas las provincias andaluzas más Barcelona y Madrid por razones obvias y al igual que había hecho Tierras del Sur. La lista de colaboradores fue aumentando en el staff. El último número registraba los siguientes nombres: Antonio Gala, que publicó un artículo en el número 1 saludando a la nueva revista, Manuel Alcántara, José Infante, Alfonso Canales, José Mayorga, Rafael Pérez Estrada, Francisco Cortés, Julián Sesmero, Luciano G. Ossorio, Gonzalo Rojo y Jim Hollander, éste último como colaborador fotógrafo.

En otro de los párrafos de la "Carta del director" a la que aludíamos al iniciar este trabajo, Francisco Lancha afirma: "Pretendemos que ALGARABÍA (sic) haga honor a su nombre y se convierta en el grito andaluz ante Andalucía misma y que sea al mismo tiempo portavoz de sus inquietudes (...) en el campo social, económico, agrícola, industrial, laboral y político y sin que el orden de los factores, jamás nos altere el producto" (núm. 0, pág. 5) ${ }^{13}$.

\section{Andalucía actualidad}

Tras la desaparición en 1979 de Tierras del Sur no había aparecido en el mercado andaluz ninguna revista con pretensiones de llegar a toda la Comunidad Autónoma y a los núcleos peninsulares de la emigración andaluza, salvo el caso del mensual Andalucía Económica, que aún se edita, pero

\footnotetext{
12 Datos que me han sido facilitados oralmente por Francisco Lancha.

${ }^{13}$ El lector podrá encontrar una información más detallada sobre esta revista en REIG, Ramón: Las revistas andaluzas de la transición (1974-79) y el caso de "Algarabía” en Revista de Estudios Andaluces, número 17, Universidad de Sevilla, 1991, pp. 63-84.
} 


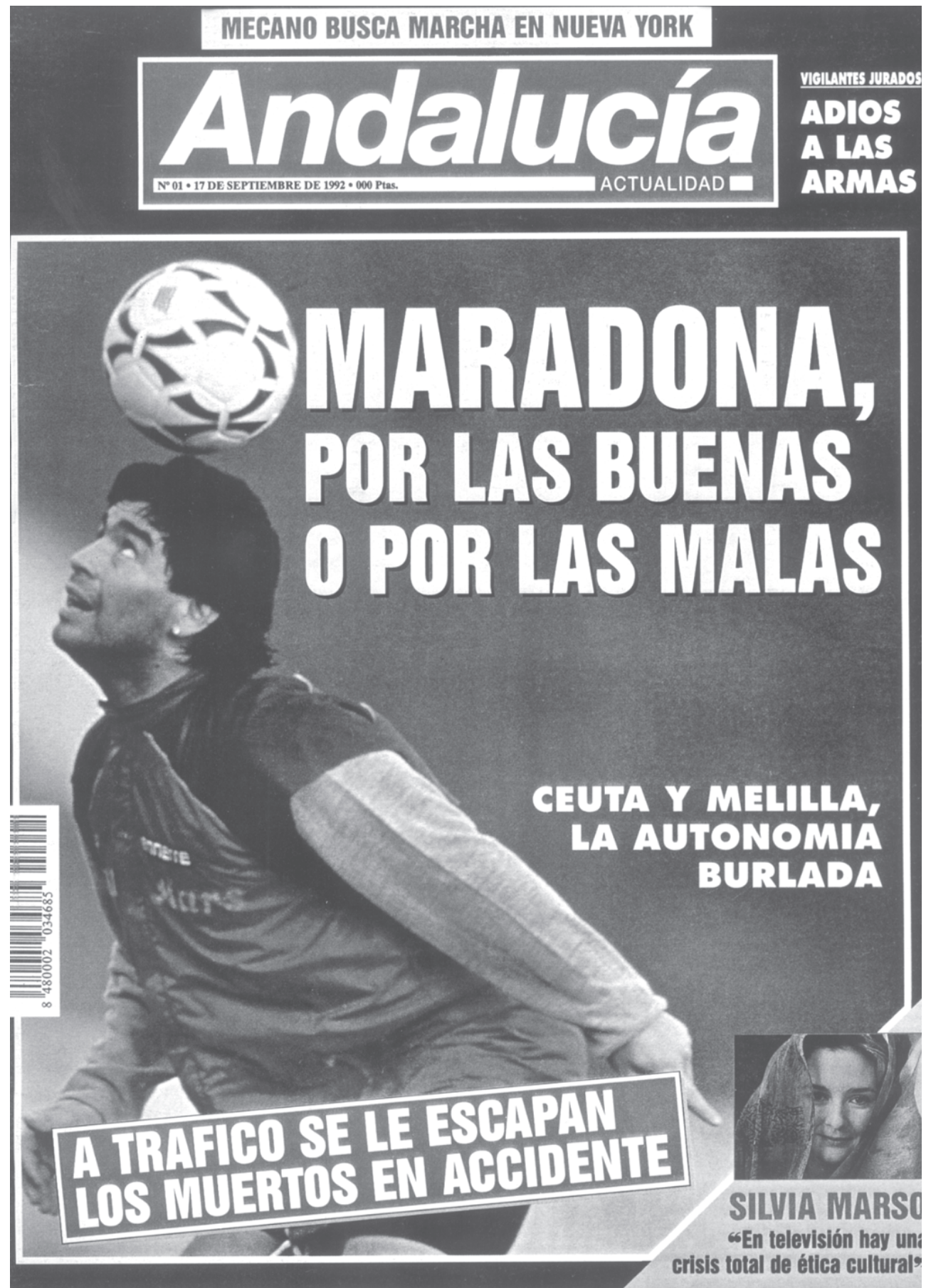


que debe su existencia a la iniciativa, en primera instancia, del capital catalán impulsor de la revista Economics. Ambas publicaciones escapan a las pretensiones de este trabajo.

Es el 8 de octubre de 1992 cuando hace su aparición el número 1 del, por ahora, último fracaso de la iniciativa privada andaluza en materia de información escrita con formato de revista. De Andalucía Actualidad, concebida como semanario y con redacción central en Sevilla, únicamente van a salir a la calle quince números, el último de ellos el 14 de enero de 1993. Su diagramación y formato, así como su propia cabecera, recuerdan a las revistas estatales Tiempo o Tribuna de Actualidad. Sus contenidos van a ir más allá de los temas andaluces para alcanzar acontecimientos estatales que se proyecten en Andalucía. Este aspecto conllevará que la publicación entre en competición directa con los grandes semanarios nacionales como por ejemplo los citados con anterioridad. Como firma "estrella" nos presentó al escritor Antonio Muñoz Molina.

Impulsor de la revista fue el empresario de la construcción Juan Manuel Sanz, natural de Bornos (Cádiz), quien aglutina al grupo empresarial CADES. Sanz residió en los años 70 en Barcelona, donde estaba vinculado al entonces Partido Socialista de Andalucía-Partido Andaluz (PSA-PA), hoy Partido Andalucista. Cuando en los años 80 se traslada a Andalucía su vinculación con esta formación política deja de ser tan estrecha como antes. El auge que en esa década de los 80 experimenta la construcción en España beneficiará también al grupo empresarial de Juan Manuel Sanz y revalorizará su patrimonio. Esta circunstancia le lleva a pensar en crear una revista a pesar de su déficit considerable de conocimiento respecto al funcionamiento de las industrias de la información.

Sanz entró en contacto con el ex-alcalde de Sevilla (1979-1983), Luis Uruñuela, uno de los fundadores del partido antes mencionado junto a Alejandro Rojas-Marcos y Miguel Ángel Arredonda, entre otros. Uruñuela va a encabezar una lista de cincuenta socios fundadores de Andalucía Actuali$d a d$, entre los que se encuentran los catedráticos de la Universidad de Sevilla Manuel Delgado Cabeza, Isidoro Moreno Navarro o Gabriel Cano, además de otras personalidades influyentes en el mundo intelectual andaluz como es el caso de Francisco Ruiz Morcillo.

Este grupo de fundadores, que se caracteriza por su independencia respecto del poder oficial representado por el PSOE (además, salvo el citado Uruñuela ninguno de los restantes militaba en partido alguno), 


\section{Andalucín Las empresas Andalicia as de la construcción}

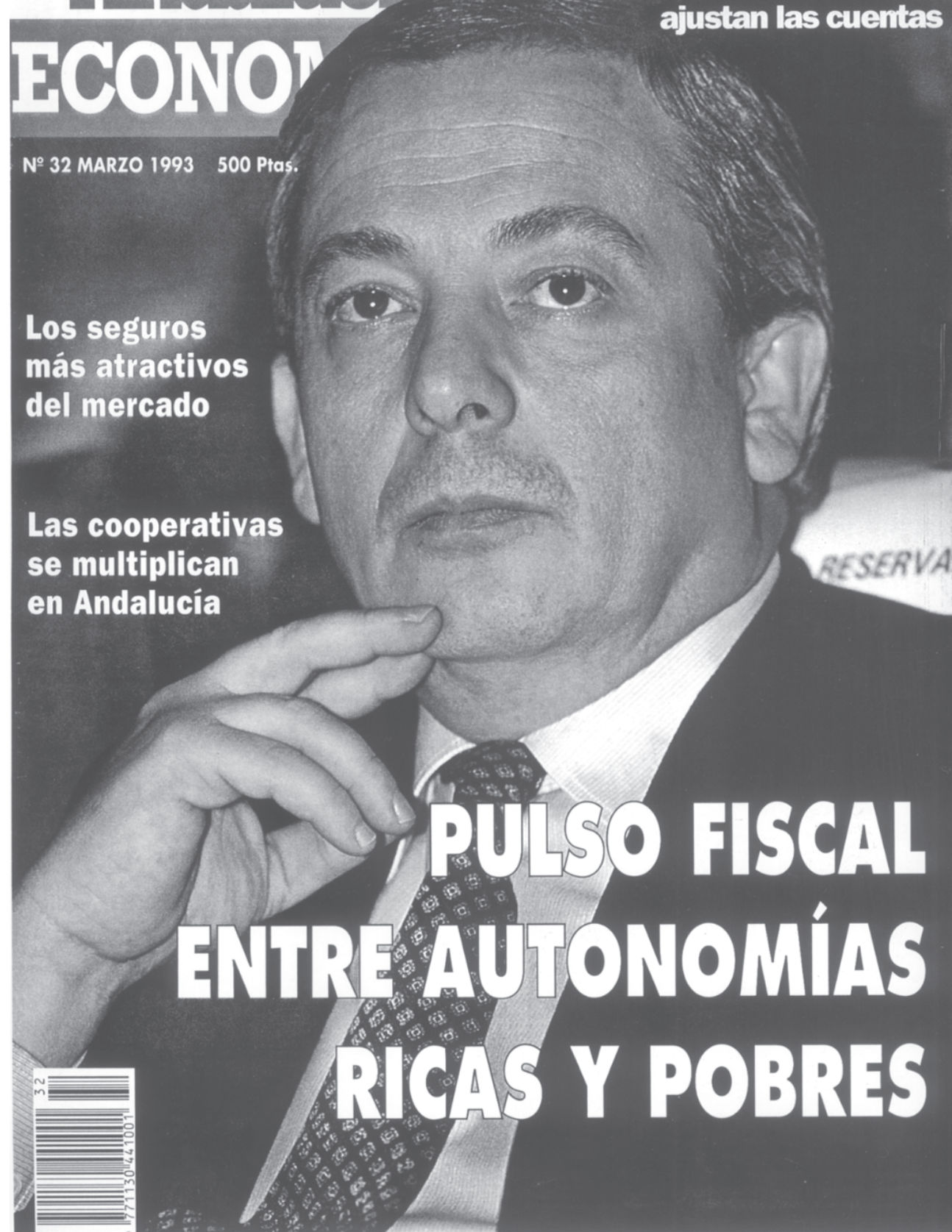


eligió como director al periodista Antonio Checa Godoy, nacido en Jaén en $1946^{14}$.

Los cincuenta socios fundadores, entre los que se encontraban Juan Manuel Sanz y otros empresarios vinculados a su grupo, constituyeron Medios de Comunicación de Andalucía, S.A., cuyo capital social inicial, desembolsado en su totalidad por los socios impulsores de la revista, ascendía a 10 millones de pesetas. El grupo empresarial de Sanz, que además invirtió en los gastos de funcionamiento de la revista (redacción, formada por 30 personas, ordenadores, etc.), estimaba que con 100 millones de pesetas la revista podría mantenerse en el mercado durante un período de entre seis y doce meses.

Sin embargo, pronto los costes de publicación, sobre todo, iban a demostrar lo erróneo de este cálculo. Al mismo tiempo, el grupo empresarial sufrió una alarmante crisis que llegó incluso a costarle la retirada crediticia del Banco Hipotecario, principal valedor de las empresas del sector de la construcción.

Inesperadamente, Juan Manuel Sanz decide hacer desaparecer la revista, a pesar de que el Consejo de Administración, encabezado por Manuel Delgado Cabeza, había propuesto alguna vía alternativa como convertir en mensual al semanario. Delgado Cabeza considera que en tres meses de vida no había sido posible llevar a cabo un balance real de las posibilidades de implantación de la revista ${ }^{15}$. Asimismo, Manuel Delgado Cabeza especula con la posibilidad de que haya existido cierto obstruccionismo por parte del poder político a una revista no controlada por él, si bien el director de Andalucía Actualidad, Antonio Checa, sostiene que el entonces Portavoz del Gobierno de Andalucía, José Nevado, le negó personalmente todo interés del PSOE por influir en el cierre del semanario ${ }^{16}$.

No obstante, la realidad objetiva pone de manifiesto que ninguna de las grandes empresas andaluzas (Sevillana de Electricidad, Abengoa, Cobreros, etc.), a pesar de ser requeridas para ello ${ }^{17}$, se mostraron proclives a invertir en la nueva publicación, circunstancia que es interpretada por Delgado Cabeza como un desinterés de los grandes poderes empresariales andaluces respecto a una publicación autóctona de Andalucía.

\footnotetext{
${ }^{14}$ Checa Godoy, citado ya con anterioridad, es, además de periodista, profesor de la Facultad de Ciencias de la Información de la Universidad de Sevilla y un excelente investigador de la prensa andaluza como lo demuestra su Historia de la prensa andaluza, Fundación Blas Infante, Sevilla, 1991, o su libro Historia de la prensa en Iberoamérica, Ediciones Alfar, Sevilla, 1993.

15 Delgado Cabeza en declaraciones a quien suscribe.

${ }^{16}$ Checa en declaraciones a quien suscribe.

17 Declaraciones de Delgado Cabeza y de Checa Godoy a quien esto suscribe.
} 
Cuando el grupo de Juan Manuel Sanz decide dejar de respaldar a la revista ésta había alcanzado una tirada de 8.000 ejemplares. La estimación de rentabilidad o, al menos de amortización de gastos, exigía una tirada de entre 12.000 y 14.000 ejemplares. El pasivo acumulado fue de 100 millones de pesetas, liquidado actualmente.

Aunque aún están por investigar si las razones que impulsaron a Juan Manuel Sanz y su grupo de empresarios a dejar de apoyar a Andalucía Actualidad fueron económicas o políticas (o de ambos aspectos), lo cierto es que estamos ante lo que, por ahora, es el último fracaso de una revista editada desde Andalucía y con capital andaluz.

\section{Conclusiones}

1. Se constata el fracaso de la iniciativa privada andaluza tanto en el terreno de la edición de revistas como, tal vez derivado de ello, en el campo del conocimiento de las industrias culturales de la información. Igualmente se observa una falta de interés en el empresariado andaluz por este sector de la economía.

2. Los tres semanarios andaluces de la transición reseñados, Tierras del Sur, Torneo y Algarabía, tenían un enfoque a la vez empresarial y andalucista, sobre todo Tierras del Sur (la "aventura" empresarial que se demostró más sólida de todas). La ideología de Tierras del Sur y de Algarabía puede calificarse como de liberal o de centro izquierda no marxista; la de Torneo como de izquierda marxista. Por su parte, La Ilustración Regional ofrece un claro predominio como revista ideológica antes que proyecto empresarial, impulsada por miembros de una clase social perteneciente a la Andalucía liberal e ilustrada.

3. Ya en nuestros días Andalucía Actualidad, a pesar de que sus fundadores no estaban vinculados al poder socialista, no ofrecía en sus mensajes, genéricamente considerados, una confrontación abierta y sistemática contra dicho poder, sino más bien un afán de crítica constructiva.

4. Ninguna de las revistas citadas ha logrado una implantación entre el público andaluz, bien por fallos empresariales, bien por falta de conciencia regional o nacionalista andaluza, o bien por ambos motivos.

5. Todas las revistas mencionadas pretendían proyectarse más allá de Andalucía: hacia la emigración en Cataluña y Madrid, sobre todo.

6. En las revistas del período 1974-1979 fueron temas fijos Andalucía como Comunidad históricamente marginada, el problema de la tierra y el 
pensamiento de Blas Infante junto a los episodios más notorios del nacionalismo o andalucismo. A estos temas Andalucía Actualidad añadirá otros de importancia nacional como el de los inmigrantes del Magreb, la situación de Andalucía después de la Expo de 1992 o la incidencia de la mafia en las costas andaluzas.

7. A excepción de Algarabía, que la tenía en Málaga, el resto de las publicaciones sobre las que hemos tratado, establecieron su redacción central en Sevilla, y, salvo La Ilustración Regional, más orientada al pensamiento, un conjunto de corresponsales periodistas. 